Article

\title{
Design and Experimental Evaluation of Innovative Wire-to-Plane Fins' Configuration for Atmosphere Corona-Discharge Cooling Devices
}

\author{
Mar Cogollo ${ }^{1,2, *}$, Pedro M. Balsalobre ${ }^{2}$, Andrés Díaz Lantada ${ }^{1}$ and Héctor Puago ${ }^{2}$ \\ 1 Product Development Laboratory, Department of Mechanical Engineering, Universidad Politécnica de \\ Madrid, 28006 Madrid, Spain; andres.diaz@upm.es \\ 2 Research \& Development Department, Cedrión, Consultoría Técnica e Ingeniería. S.L, 28919 Leganés, Spain; \\ p.marti@cedrion.com (P.M.B.); h.puago@cedrion.com (H.P.) \\ * Correspondence: adiaz@etsii.upm.es; Tel.: +34-91-336-3120
}

Received: 9 January 2020; Accepted: 31 January 2020; Published: 4 February 2020

\begin{abstract}
Electro-fluid-dynamic cooling devices (EFAs) are being recognized due to their enormous advantages for their application in several industrial sectors, their performance benefits from generated ionic winds and their singular features, which make them competitive with conventional fans and heatsinks. Due to the problems in the electronics industry, where traditional refrigeration systems are not effective due to their dimensions, this study analyzes an innovative arrangement based on wire-to-plane fins by direct current (DC) positive corona discharge in atmospheric air for applications. The paper focuses on optimizing the multicriteria geometry of the electrodes. Several parameters are analyzed such as the gap between emitter and ground electrodes, the electrode materials and geometry, the diameter of the high-voltage electrode and the influence of the dielectric barriers located near the corona electrode to improve heat exchange. Experimental validation shows the potential of this arrangement related to weight, volume, non-mobile parts and silence.
\end{abstract}

Keywords: cooling devices; positive corona discharge; electro-hydro-dynamic phenomena; industrial applications; prototype

\section{Introduction}

Electrohydrodynamic flow (EHD) [1] caused by corona discharge is the branch of science that studies the movement of a fluid under a non-uniform electric field and develops technology based on these studies. Through the corona discharge, gas molecules near corona electrode are ionized when a high-intensity electric field is applied between a highly curved corona electrode and a ground electrode. There are different corona-discharge configurations according to electrode geometries, the most relevant being wire-to-plane [2-4], wire-to-cylinder [5], needle-to-plane [6,7], needle-to-ring [8] or wire/needle-to-grid [9]. Research on corona discharge has been carried out in different media highlighting the investigations in atmospheric air with standard conditions, although more recently, many refrigerants such as R113 [10,11] R114 [12] R134a [13] have been studied. On the other hand, gases such as nitrogen [14], carbon dioxide, helium or argon [15] were also analyzed. Considering atmospheric air, when the dielectric breakdown of the air is reached (approximately $\mathrm{E}=3 \times 106 \mathrm{~V} / \mathrm{m}$ ), the ionization of the air molecules around the high-voltage electrode induces a corona discharge. Due to the electric field, these ions are subjected to the Coulomb force, creating a movement from the corona electrode to the ground electrode. The set of all these Coulomb forces gives rise to an electrohydrodynamic force field originating in the corona discharge. The presence of the electric field and the multiple collisions between ions and neutral air molecules that are in the area of the 
discharge produce a fluid flow called "ionic wind". This ionized fluid can be used in multiple industrial applications, such as cooling devices [16-18] and others.

In recent years, new advances in electronic systems are producing an increase in the heat flux density generated in equipment. The result of increasing power and miniaturization causes thermal control to be a critical factor in this industry. Due to the generation of local heating areas, these components have a high heat flux for a small heat exchange surface which directly influences the performance of their components.

Currently, the microelectronics industry utilizes traditional cooling systems such as rotary fans, heatsinks or heat-pipes. These systems have been valid so far due to their high efficiency, since they represent a mature, well-known and economical technology. However, when the size of these devices is reduced their behavior changes abruptly and, as a result, their performance decreases considerably. In addition, the design of small-scale centrifugal fans and heatsinks, the high manufacturing costs, and the rotation speed are challenges in the industry when it comes to competition and implementation [19-21]. Therefore, new generation electronic components require alternative cooling systems that can transfer this amount of heat and maintain the useful life and performance of the components. In addition, the requirements demanded by the microelectronic sectors must be achieved to be sufficiently small and noiseless and without adding additional volume or weight to the component.

Over the last 10 years, the use of electrohydrodynamic refrigeration has been considered as a technology with potential to replace traditional refrigeration devices due to the large number of advantages it presents and its possible application in several industrial sectors. The first observation on electrohydrodynamic effects took place in 1629 by N. Cabeo [22], however, the official discovery of the existence of the EHD force has been attributed to F. Hauksbee in the 18th century. Over the new few years, several studies were published by scientists like Newton [23], Faraday [24] or Maxwell [25] who investigated the EHD effect, with Wilson [26] being the first to use the term of electric wind. Later, ionic wind behaviour was studied in the 1960s by Robinson [27], who measured electric-wind velocity (approximately, $4 \mathrm{~m} / \mathrm{s}$ ) and an energy conversion efficiency lower than $1 \%$. Its goal was to evaluate the electrohydrodynamic fluid for its application to create EHD blowers which could substitute traditional mechanical fans. Kalman et al. [28], Rashkovan et al. [29] and Ramadhan et al. [30,31] focused on optimizing the wire-plane configuration to be incorporated in an EHD blower with the aim of refrigerating electronic components and enhancing their efficiency. A mathematical and computational 2D and 3D model of this electrode configuration was developed under different conditions of electrode gap and applied voltage in order to determine an optimal design for use in heat transfer.

However, the first real application was carried out by Jewell-Larsen et al. [32,33] who developed a small-scale EHD fan based on the wire-plane configuration. Their analytical and experimental results showed the performance of the electric wind is related to the pressure and the flowrate of the blower and determines that the corona devices are promising cooling devices to integrate them into electronic systems.

Research carried out shows that devices with integrated corona discharge technology are an alternative to consider improving the efficiency and lifetime of electronic systems which present fluidic and thermal problems such as the effect of boundary layer, temperature distribution and or heat transfer. Nevertheless, this corona phenomenon is a sensitive technology that depends on many design parameters and material selection.

In the present study, we propose an alternative based on an innovative wire-to-plane fins configuration for EHD cooling systems which we refer to as TRAID, specific label (Figure 1). This new geometric arrangement of the electrodes is based on the patent [34] by CEDRION C.T.I. S.L 


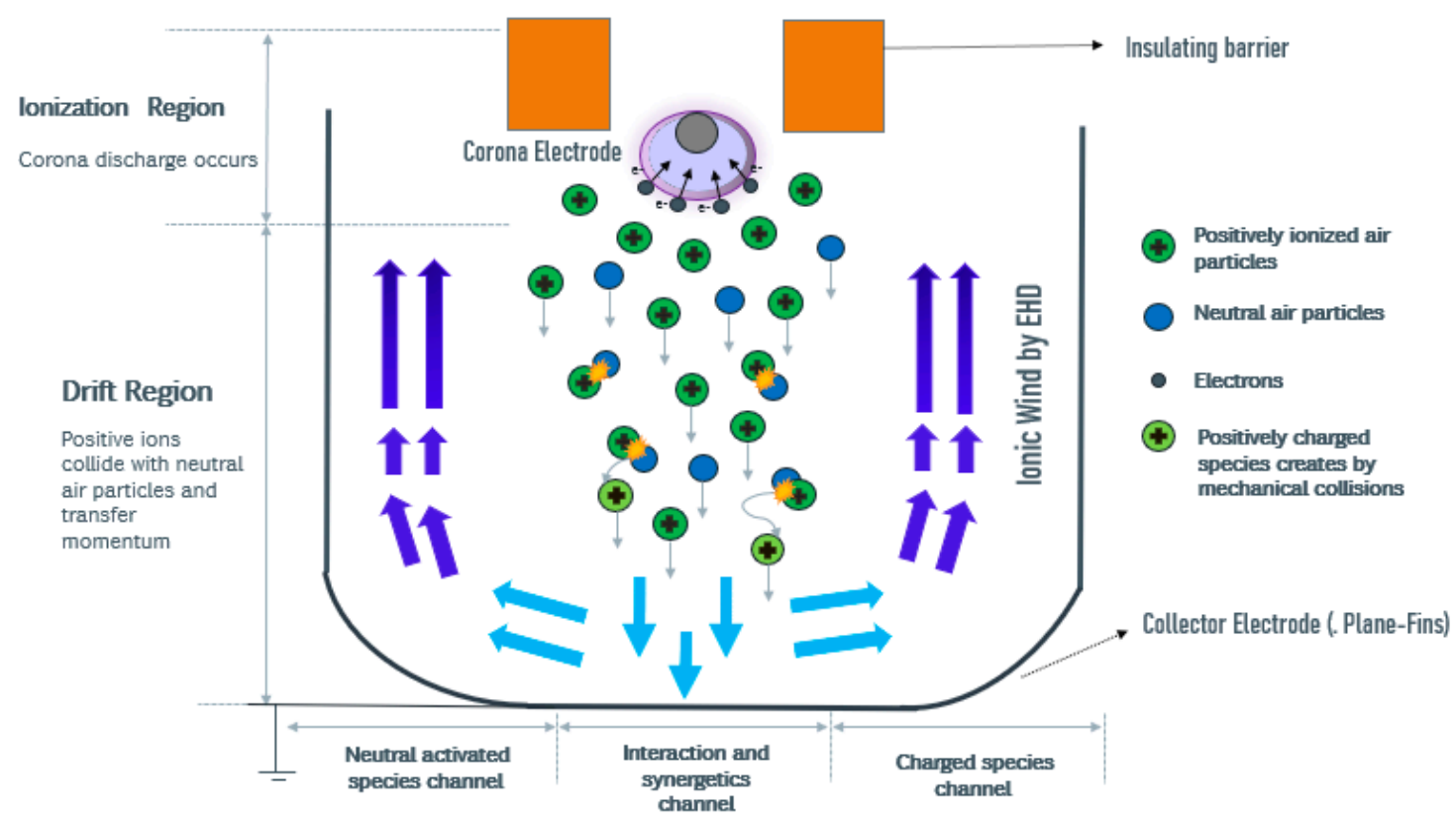

Figure 1. Representation of a positive corona discharge with wire-to-plane fins geometry.

\section{General Considerations}

Before describing the materials and methods used in present study, this section presents the general considerations and equations describing EHD cooling phenomena.

\subsection{Electrohydrodynamic Fundamental Equations}

Ionic wind generated by corona discharge is produced by the interaction between the electric charges and the neutral air particles movement. This EHD airflow can be described by the following equations:

In the air, the electric potential difference is governed by Poisson's equation:

$$
-\nabla^{2} V=\frac{q}{\varepsilon_{o}}
$$

where $q$ is the space charge density $\left(\mathrm{C} \cdot \mathrm{m}^{-3}\right)$ and $\varepsilon_{o}$ is the dielectric permittivity of the free space $\left(=8.854 \times 10^{-12} \mathrm{C} \cdot \mathrm{V}^{-1} \cdot \mathrm{m}^{-1}\right)$. This voltage $(\mathrm{V})$ is described from intensity of electric field $\vec{E}$ by:

$$
\vec{J}=\mu_{i} \vec{E} q+\vec{U} q-D \vec{\nabla} q
$$

where $\mu_{i}$ is the mobility of air ions, $\vec{U}$ is the airflow velocity vector and $D$ is the ionic diffusivity coefficient. Current continuity condition provides the equation for the current density:

$$
\begin{gathered}
\rho_{\text {air }} \vec{U} \cdot \nabla \vec{U}=-\nabla p+\mu_{\text {air }} \nabla \vec{U}+q \vec{E} \\
\nabla \cdot \vec{U}=0
\end{gathered}
$$

where $\rho_{\text {air }}$ is the air density $\left(\mathrm{kg} \cdot \mathrm{m}^{-3}\right), p$ is the air pressure $(\mathrm{Pa}), \mu_{\text {air }}$ is the air dynamic viscosity and the term of $q \vec{E}$ defines Coulomb force $\left(\mathrm{N} \cdot \mathrm{m}^{-3}\right)$. 


\subsection{Heat-Transfer Equations}

The general heat-exchange equation can describe precisely the energy accumulated in the mass electrode. This provides a relationship between heat flux and the temperature of the system.

$$
\mathrm{mc} \frac{\mathrm{dT}}{\mathrm{dt}}=\dot{\mathrm{Q}}+\dot{\mathrm{Q}}_{\mathrm{cor}}+\operatorname{A\sigma \varepsilon }\left(\mathrm{T}^{4}-\mathrm{T}_{\mathrm{atm}}^{4}\right)-\mathrm{Ah}\left(\mathrm{T}-\mathrm{T}_{\mathrm{atm}}\right)
$$

where $\mathrm{m}$ is the mass of the mass electrode $(\mathrm{kg}), \mathrm{c}$ is the specific heat capacity of the metal $\left(\mathrm{J} \cdot \mathrm{kg}^{-1} \cdot \mathrm{K}^{-1}\right)$, $\mathrm{T}$ is the temperature of the mass electrode $(\mathrm{K}), \dot{\mathrm{Q}}$ is the heat flux of the heat source $(\mathrm{W}), \mathrm{A}$ is the surface of the mass electrode $\left(\mathrm{m}^{2}\right), \sigma$ is the Stefan-Boltzmann constant $\left(5.67 \times 10^{-8} \mathrm{~W} \cdot \mathrm{m}^{-2} \cdot \mathrm{K}^{-4}\right), \varepsilon$ is the emissivity of the metal, $\mathrm{T}_{\mathrm{atm}}$ is ambient temperature $(\mathrm{K})$, and $\mathrm{h}$ is heat transfer coefficient $\left(\mathrm{W} \cdot \mathrm{m}^{-2} \cdot \mathrm{K}^{-1}\right)$.

Assuming the radiation term is negligible, considering steady state, and hypothesizing that $\dot{\mathrm{Q}}_{\text {cor }}$ is practically the power consumption of the discharge, heat equation can be rewritten as follows [35]:

$$
\mathrm{T}-\mathrm{T}_{\mathrm{atm}}=\mathrm{R}_{\mathrm{th}} \cdot\left(\dot{\mathrm{Q}}+\dot{\mathrm{Q}}_{\mathrm{cor}}\right)
$$

where $\dot{Q}_{\text {cor }}$ is the heat flux induced by corona discharge $(W)$, and $R_{t h}=A^{-1} \cdot h^{-1}$ is the thermal resistance of the system. The term $\dot{\mathrm{Q}}_{\text {cor }}$ is a function of temperature and power consumed by the corona discharge, and can be approximated in the first order with the equation:

$$
\dot{\mathrm{Q}}_{\mathrm{cor}}=\mathrm{Ah}\left(\mathrm{T}_{\text {cor }}-\mathrm{T}_{\mathrm{atm}}\right)=\mathrm{P}_{0, \mathrm{cor}}+\xi\left(\mathrm{T}-\mathrm{T}_{\mathrm{atm}}\right)
$$

where $\xi$ is the variation of corona power with temperature parameter, a constant determined experimentally, and $\mathrm{P}_{0, \text { cor }}$ is power consumption (W) at ambient temperature. Finally, we can model the system behaviour like in the form:

$$
\dot{\mathrm{Q}}+\mathrm{P}_{0, \mathrm{cor}}=(\mathrm{Ah}-\xi) \cdot\left(\mathrm{T}-\mathrm{T}_{\mathrm{atm}}\right)
$$

This equation shows an inherent residual heat flux and thermal resistance derived from corona discharge. Accordingly, power consumption and thermal resistance would define the global performances in each geometry. Power is imposed by voltage supply and geometry (gap, barriers, among others) and thermal resistance can be determined experimentally. The higher the heat transfer coefficient $h$, the lower the thermal resistance, so a higher heat flux could be dissipated for the same temperature. Therefore, geometry optimization will focus in decrease thermal resistance, keeping constants mass and volume.

\section{Materials and Methods}

The investigation has allowed us to characterize this new configuration from an electrostatic and thermal point of view. On the one hand, the representative current-voltage $(\mathrm{C}-\mathrm{V})$ curve, optimize the inter-electrodes spacing in a range of $1-3 \mathrm{~mm}$ and the wire diameter of the corona electrode with 25 , 50 and $100 \mu \mathrm{m}$ have been studied. Consecutively after an analysis of the corona discharge, a TRAID prototype was designed and thermal dissipation was studied in a metallic-plane piece after integrating this device. All experiments were executed in dry air at atmospheric pressure.

\subsection{Innovative Geometrical Configuration and Design Parameters}

Two electrodes with a high aspect-ratio create an electric corona discharge when an elevated DC electric field is applied between them. Considering a positive polarity, the innovative configuration studied is based on as a micrometric wire as emitter and a collector electrode with a convergent shape (plane-fin combination) [28]. In addition, with the aim of separate the inlet and outlet of the fluid, dielectric barriers have been integrated into the sides of the wire, which have a determined 
thickness $t$ and height $H$. A sketch of the experimentally studied TRAID configuration is shown in Figure 2A. Several geometric parameters are analyzed in this document, which are summarized in Table 1. The materials selection as emission electrode are tungsten and stainless steel with diameters from 25 to $100 \mu \mathrm{m}$, correspondingly. The device studied consists of two pieces which are assembled: on the one hand, a dielectric piece that allows separation between electrodes according to the gap studied and on the other hand, the ground electrode accomplishes a pure machined aluminum bulk with convergent shape. The inter-electrode separation is examined by changeable distances of $500 \mu \mathrm{m}$ in a range from 1 to $3 \mathrm{~mm}$.

A)

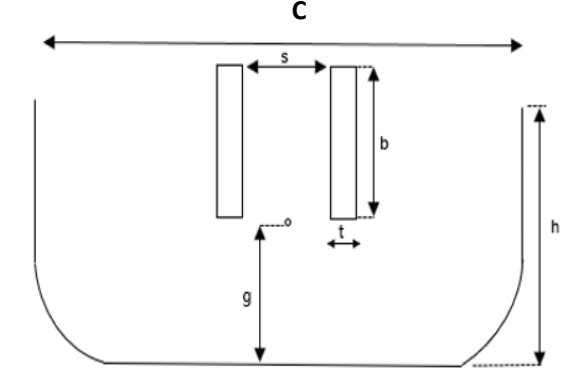

C)
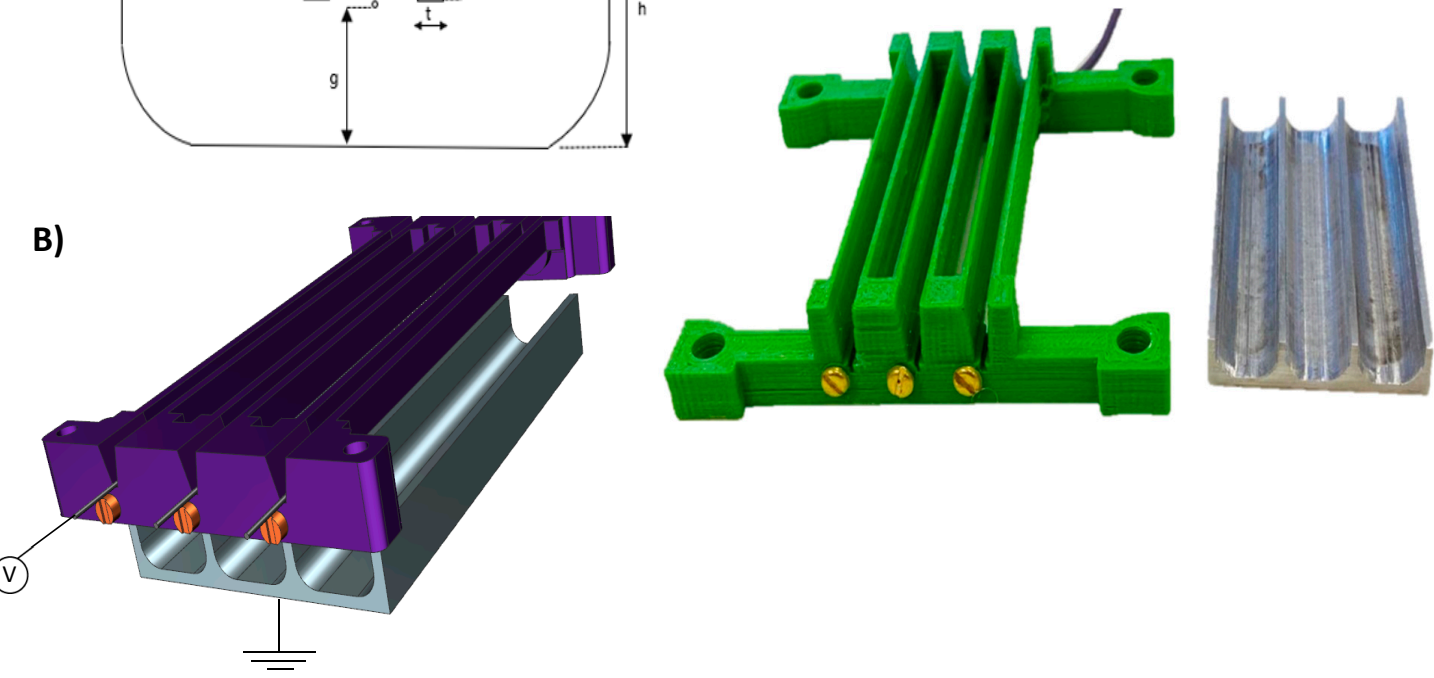

Figure 2. (A) Electrode TRAID arrangement with wire-to-plane-fins and dielectric barriers; (B) Schematic CAD design of the proposed corona device for enhancement thermal dissipation; (C) Manufacturing by 3-D printing of the dielectric piece and mechanized aluminum ground electrode.

Table 1. Geometric parameters used in this validation study.

\begin{tabular}{cc}
\hline Parameter & Value \\
\hline Applied voltage, $V e$ & 0 to $6 \mathrm{kV}, \mathrm{DC}$ \\
\hline Corona wire diameter, $d_{c}$ & $25,50,100 \mu \mathrm{m}$ \\
\hline Electrode gap, $g$ & $1,1.5,2,2.5,3$ \\
\hline Internal channel width, $C$ & $8 \mathrm{~mm}$ \\
\hline Fins/Channel height, $H$ & $6 \mathrm{~mm}$ \\
\hline Thickness of dielectric barriers, $t$ & $1 \mathrm{~mm}$ \\
\hline Dielectric barrier separation, $s$ & $2 \mathrm{~mm}$ \\
\hline Dielectric barrier height, $b$ & $3 \mathrm{~mm}$ \\
\hline Channel length, $w$ (=corona wire and grounded \\
collector length) & $50 \mathrm{~mm}$ \\
\hline Total width of the prototype device, $a$ & $28 \mathrm{~mm}$ \\
\hline Material & Wolfram, $7076 \mathrm{Aluminum}$ alloy \\
\hline
\end{tabular}


Considering the described TRAID configuration, a rapid prototype device with corona effect is designed and manufactured to improve thermal dissipation for application in electronic components. There are numerous computer-aided design and engineering (CAD) programs that help innovation and complex product development. In this study, the design is carried out using NX-8.5 which is commercial software by Siemens PLM Solutions. Figure 2B shows the schematic CAD design of the prototype used for the tests carried out in this investigation where the pattern is repeated three times across. Therefore, the manufacturing of the dielectric structure that will position the wire at a certain electrode separation is by methods of three-dimensional (3D) printing [36]. Additive-layer manufacturing is a versatile and economical set of techniques that allow to obtain pieces with sophisticated geometries in short periods of time and to affordably optimize the final design of the device, reducing its dimensions and weight. In our case, the 3D printing technology (BQ Hephestos 2) used is fused deposition modeling (FDM) in which we use acrylonitrile butadiene styrene (ABS) as the printing material (3D Smart Materials). Finally, we reach a prototype for testing whose crucial dimensions include a channel depth of ground electrode and wire length of $50 \mathrm{~mm}$, device width and height are 28 and $8 \mathrm{~mm}$ respectively (volume $=11.2 \mathrm{~cm}^{3}$ ), and a total weight of $17 \mathrm{gr}$.

\subsection{Experimental Procedure: Electrical and Thermal Measurements}

A systematic experimental procedure is carried out to evaluate the wire-to-plane fins configuration with the prototype developed consequently the corona discharge characteristics are obtained. A high voltage power supply (Heinzinger ${ }^{\circledR}$ LNC high voltage laboratory 6000-5 pos model) is used to produce the positive DC discharge. A representative scheme of the experimental set-up for this investigation is shown in Figure 2B. The wire (emitter electrode) is connected to the high-voltage DC system that has a voltage between 0 and $6 \mathrm{kV}$ and the convergent electrode is grounded. Corona experiments are performed to study the positive electric discharge phenomenon with this distribution which analyzed its electrostatic and thermal behavior. The characteristic $\mathrm{C}-\mathrm{V}$ curve and the corona onset voltage are recorded and studied with respect to the different parameters mentioned for the electrical optimization. The applied voltage is increased in distinct steps and reduced as it approaches the saturation voltage. This procedure is repeated with different voltages in the corona device, and with different geometries. Each experimental electrostatic analysis is repeated at least 10 times to achieve a greater understanding of the corona effect, as well as to analyze repeatability average of measurements for the presented configuration.

Regarding the tests to thermally characterize the performance of the devices, resistance is used as a heat source. The heat resistance value is $650 \Omega$, which is powered by "Aim-TTi PLH 250 DC Power Supply". While the corona refrigerator is moving air, the heat source is heating an isolated aluminum plate, where temperature is measured with a probe thermocouple (type K), see Figure 3 . Heat flux is changed by modifying voltage supply in a low-voltage source. The corona device is placed on the aluminum plate, with a thermal contact. The stabilized temperature of the system in different heating powers defines the temperature increase as a function of heat flux applied (an example of this result is shown in Figure 3). This curve allows to define the term $\mathbf{A h}-\boldsymbol{\xi}$ as the inverse of the slope. This procedure is repeated with different voltages in the corona device, and with different geometries. For thermal results, statistical analysis was carried out. With a sample of approximately 550 points, a normal error distribution is obtained with a standard deviation of 0.645 . The interquartile range (1053) is defined and measurements with an absolute error greater than \pm 1.5 are discarded. Extrapolating this analysis to the curves obtained from thermal resistance and heat transfer coefficient, a higher relative error level of $4 \%$ is obtained.

In order to achieve a better understanding of the aerodynamics of the device, thermal images of the flow can be helpful. The mark of the thermal flow is obtained with a thermographic photography of a paper sheet situated in the middle of the corona device flow, in longitudinal direction (direction of the wires). Those images are obtained with thermographic camera TESTO 875-1i $(160 \times 120$ pixels, $33 \mathrm{~Hz})$. 


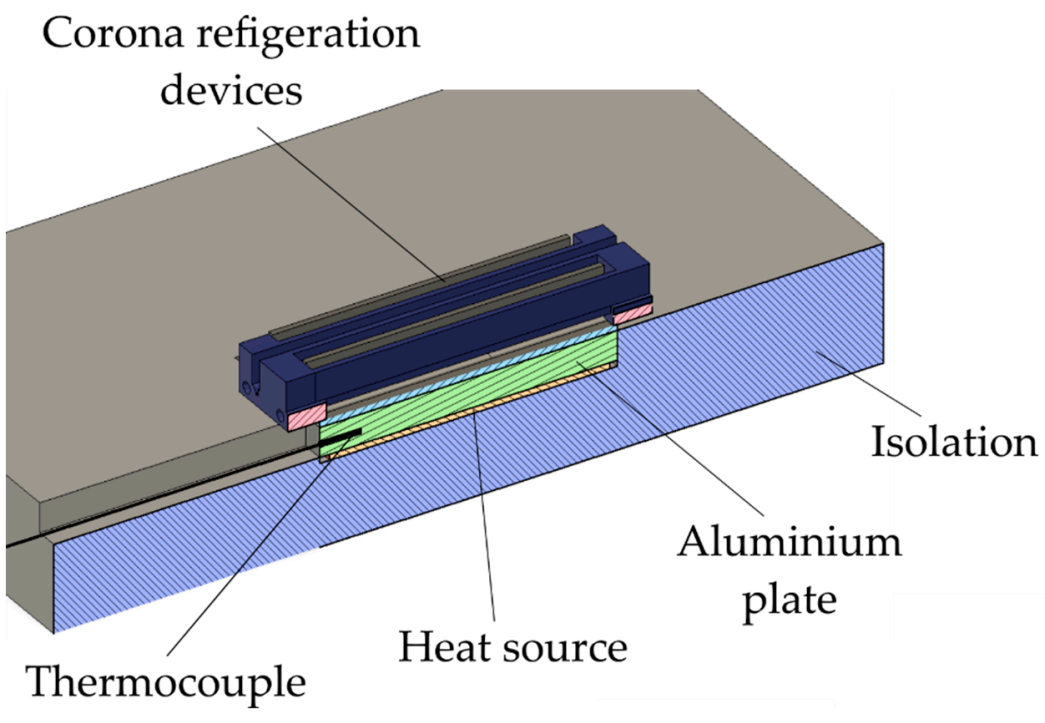

Figure 3. Schematic drawing of thermal testing set-up.

\section{Results and Discussion}

\subsection{Dielectric Barrier Effect}

The configuration studied has a characteristic feature that causes a significant change in the electrostatic behavior of the discharge caused by the dielectric barriers on the sides of the high voltage electrode. The presence of these barriers causes the electric field to be screened and lose intensity as seen in Figure 4 where wire-to-plane and TRAID geometries are compared. From the experimental evaluation, it can be understood that it is necessary to increase between 200 and $400 \mathrm{~V}$ in the TRAID configuration with the same gap compared to the wire-to-plane configuration due to these dielectric barriers that change the behavior of the electric field and it is necessary to apply additional voltage. Figure 4 shows a comparison between a thermal curve in equilibrium for three similar systems. The systems are the device turned off, the device with no dielectric barriers, and the device with dielectric barriers.

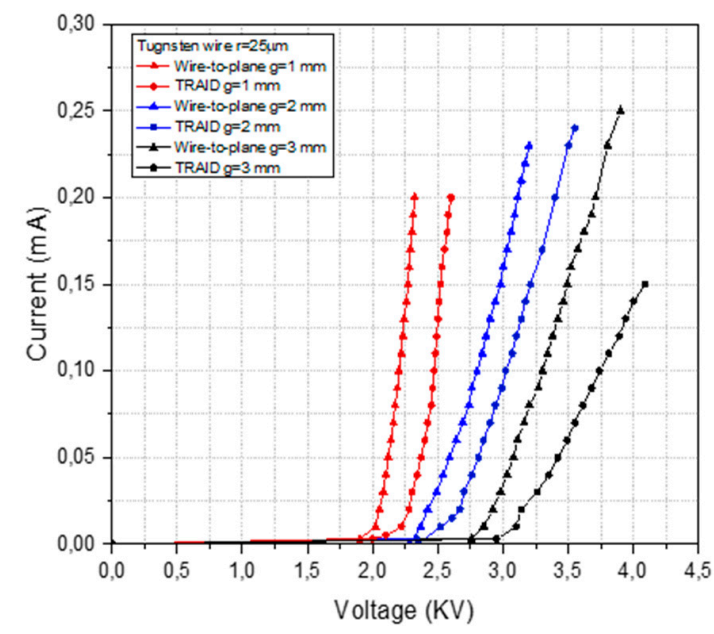

(A)

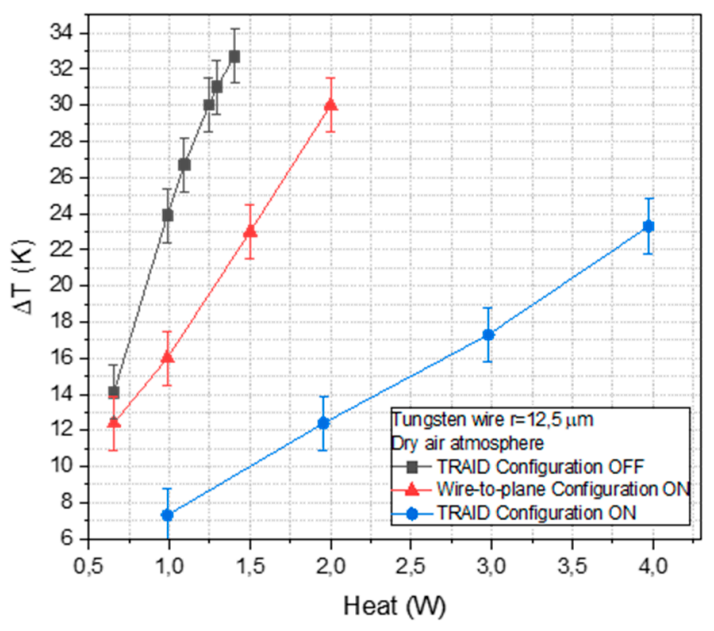

(B)

Figure 4. (A) Distinctive current-voltage $(\mathrm{C}-\mathrm{V})$ curve for comparing the typical wire-to-plane and TRAID configurations; (B) Stationary heating curve for different geometries and operation when the devices with different configuration is operating. 
The big difference between both geometries is due to a lengthwise effect that appears in the device. The outlet stream changes radically from one configuration to the other. In a no-dielectric barrier device (Figure 5A), the outlet temperature distribution is like a natural convection, meanwhile, the dielectric barriers (Figure 5B) induce a vertical jet in the middle of the device, and a lateral suction appears. This configuration improves heat transfer greatly, and maybe turbulence or recirculation effects are associated with those performances. Because of the improvement of dielectric barriers, cooling performances will be studied with this geometry. The focus in the next chapters will be variations in gap and electrode diameter.

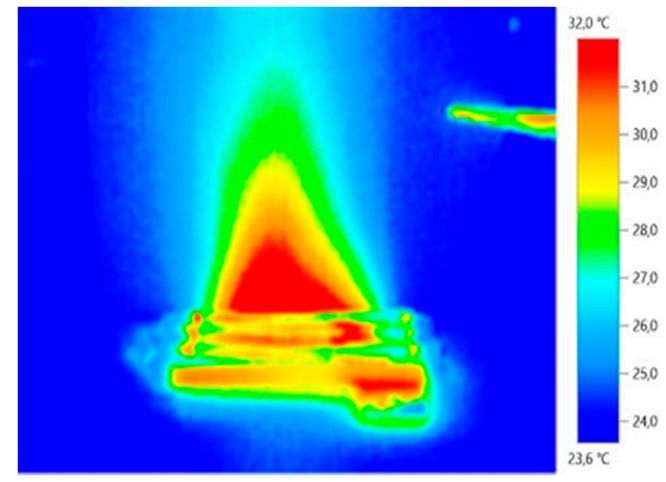

(A)

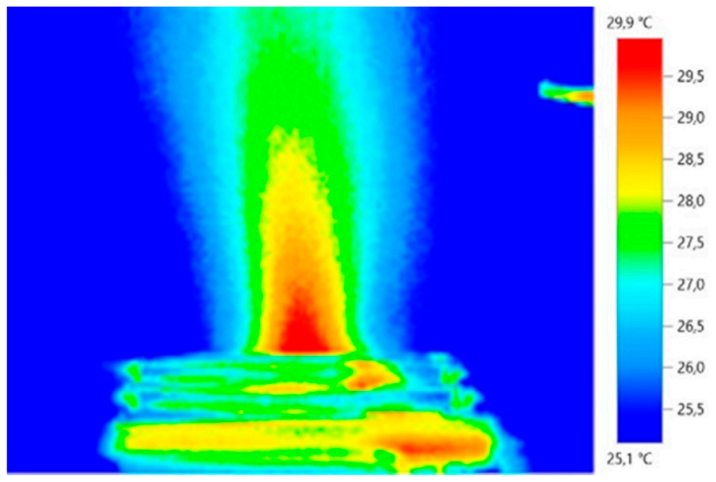

(B)

Figure 5. Thermographic photography of the outlet temperature distribution for a wire-to-plane configuration (A) and a TRAID with dielectric barriers (B).

\section{2. $\xi$ Determination}

For a constant voltage operation, intensity of the device will show variations with temperature of the system. This means an increase of the heat flux associated with the corona device. As explained above, this variation can be modelled as an additional thermal resistance to the system, caused by the corona discharge.

To define this constant experimentally, variation of the device power with temperature of the system will be evaluated. This variation appears to be constant for each geometry independent of working voltage, see Figure 6. A summary of the variation of the power device with temperature parameter for different geometries is shown in Table 2.

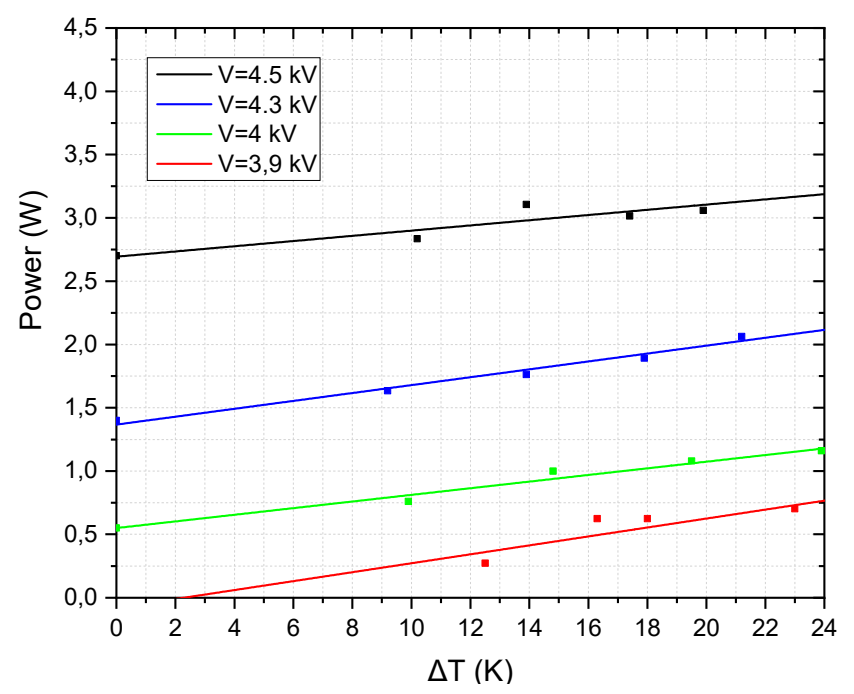

Figure 6. TRAID power consumption as a function of system temperature. 
Table 2. Variation of the power device with temperature parameter for different gaps and electrode diameters.

\begin{tabular}{cccc}
\hline$\xi(\boldsymbol{W} / \mathbf{K})$ & Gap 1.5 $\mathbf{~ m m}$ & Gap 2 $\mathbf{~ m m}$ & Gap 2.5 $\mathbf{~ m m}$ \\
\hline diameter 25 um & 0.01 & 0.014 & 0.016 \\
diameter 50 um & 0.02 & 0.025 & 0.034 \\
diameter 100 um & 0.027 & 0.03 & 0.04 \\
\hline
\end{tabular}

The parameter $\xi$ appears subtracting the term $A h$ in heat transfer equation. The ratio between those terms is around $\xi / \mathrm{Ah} \approx 0.1$, so temperature effects in corona device cannot be neglected in an accurate model.

\subsection{Electrode Radius Effect}

The geometry of the electrodes and the aspect ratio between them will be determining factors to analyze the effect of the high-voltage electrode diameter. The radius of the corona electrode must be smaller compared to the collector electrode, achieving a greater intensity of the electric field around the emitting electrode and a discharge at lower inception voltages. For a positive corona discharge for air at standard conditions, from the Peek's law [37] the critical electric field $E_{e}$ can be specified on the effective surface of the emitting electrode:

$$
E_{e}=E_{o}\left(1+\frac{2.62 \times 10^{-2}}{\sqrt{\operatorname{Re}}}\right)
$$

where $E_{o}=3.31 \times 10^{6} \mathrm{~V} / \mathrm{m}$ is the breakdown electric strength of air and the corona electrode radius Re is measured in meters. Figure 7 shows the detailed C-V curves for wires of different material (tungsten and stainless steel), with radii of 12.5, 25 and 50 microns and a separation between electrodes of $2 \mathrm{~mm}$. It is important to emphasize that the selection of the material does not have a remarkable effect on the generation of the corona discharge, as several authors have analyzed [5,38], but it is interesting to consider it to study the useful life of the device. As the radius of curvature of the corona electrode is increased, the $\mathrm{C}-\mathrm{V}$ curve shifts towards higher voltages. In some industrial applications where the operating voltage is limited, it is necessary to consider lower voltages for devices based on corona discharge technology and use small electrode radii.

Different heat-transfer coefficients $\mathrm{h}$ is obtained for thinner electrodes, see Figure 8. A bigger diameter seems to be more efficient in power consumption, but it requires higher voltages. A thicker corona electrode requires a higher voltage to start discharge, because of a lower concentration of electric field, see Figure 6, because of that, for the same power consumption, thinner electrodes will present a lower voltage, and acceleration of particles will be weaker. This means a higher air flow and an improvement in heat transfer. 
A)

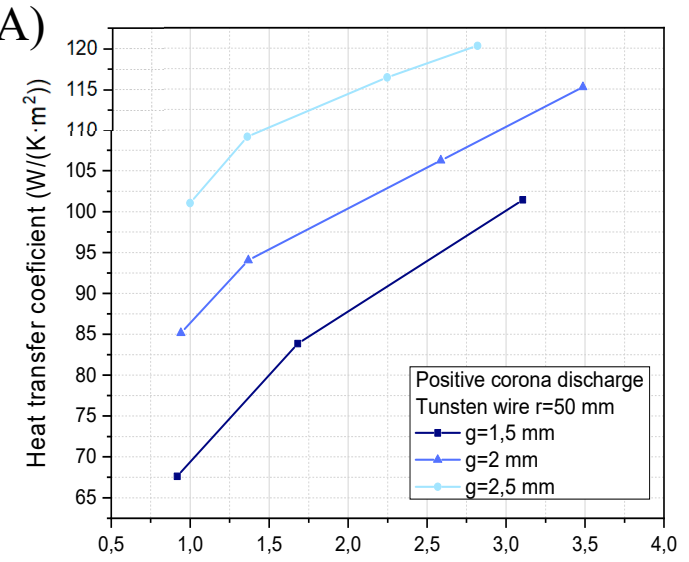

C)

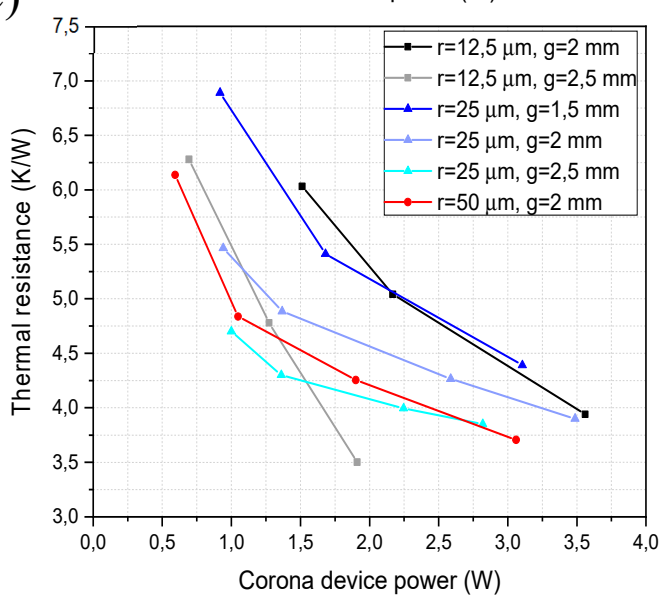

B)

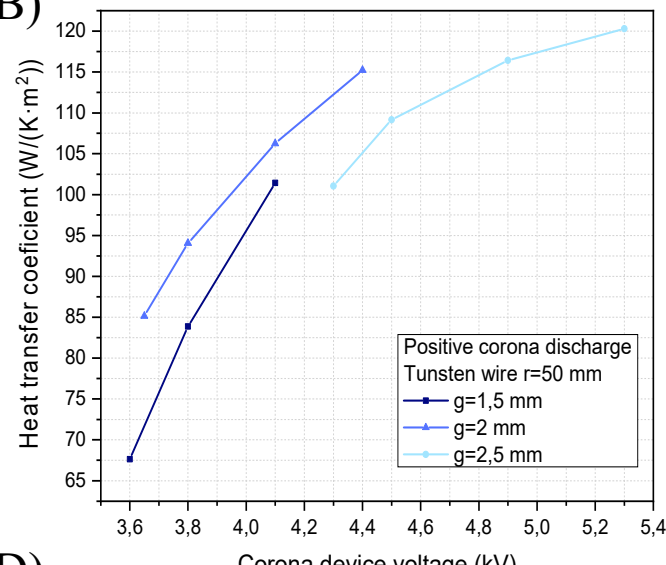

D)

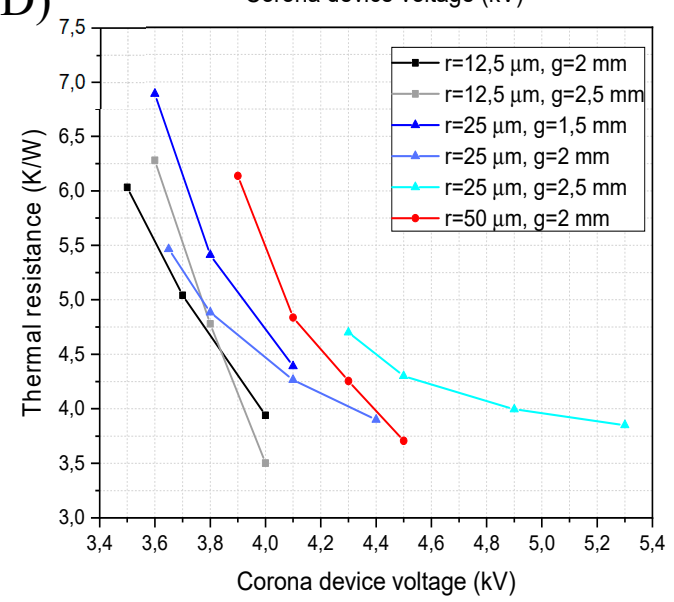

Figure 7. Wire radius consequence on the current-voltage curves for positive polarity.

A)

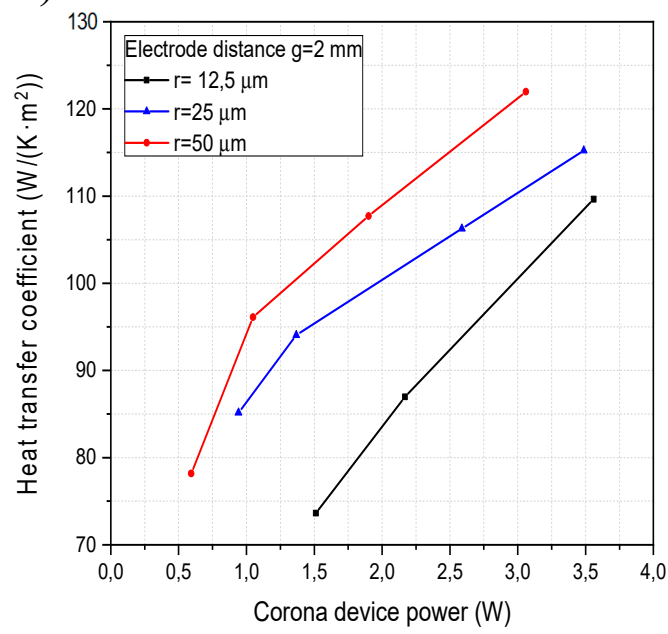

B)

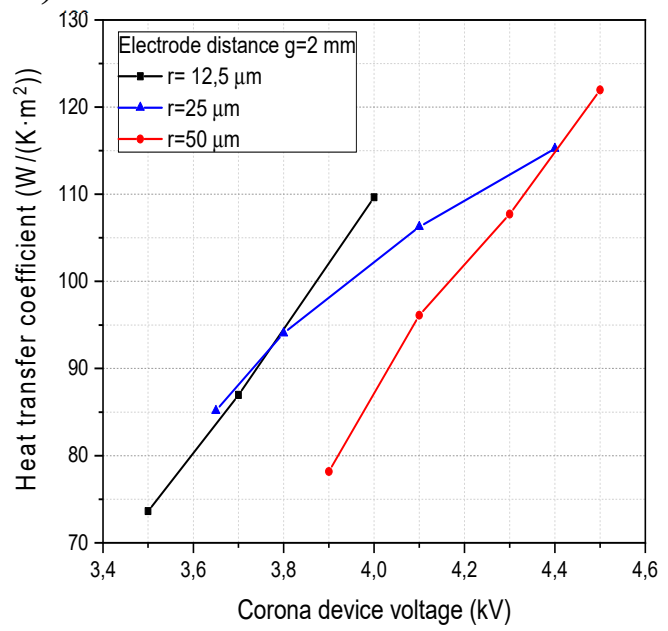

Figure 8. (A) Heat-transfer coefficient for different electrode diameter as a function of device power and (B) operating voltage with an inter-electrode separating $2 \mathrm{~mm}$.

\subsection{Effect of Inter-Electrode Separating}

The distance between electrodes is analyzed in this study by variations in current versus voltage curve for different gaps and emitter electrode radii. As can be seen in Figure 9, as we increase the separation between electrodes, the spatial distribution in the drift zone is smaller, reducing the corona 
discharge current. For each increase of half millimeter gaps, it is necessary to increase approximately $200 \mathrm{~V}$ to $500 \mathrm{~V}$ to produce the dielectric breakdown of the air and generate the corona discharge. The behavior, as can be seen in Figure 10, is applicable for the different radius with the inter-electrode separating studied.

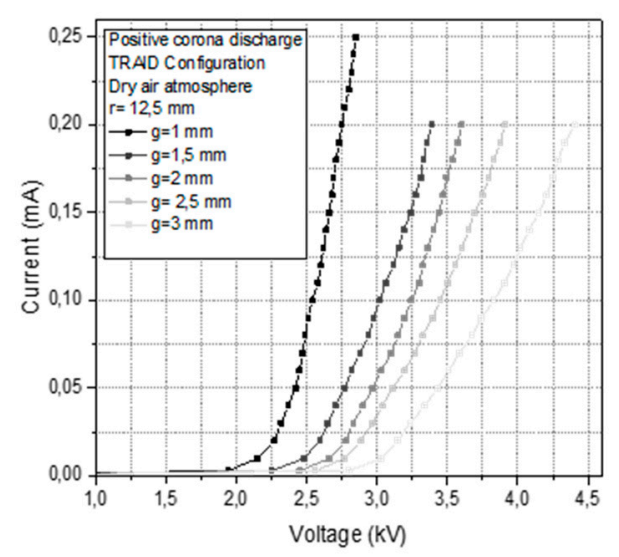

(A)

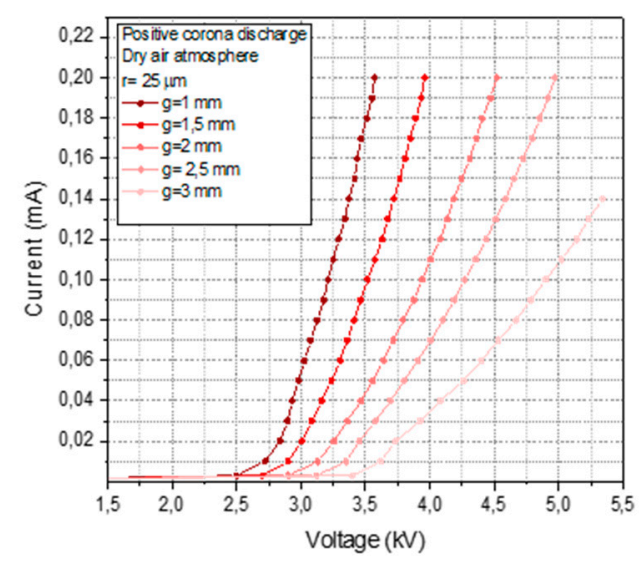

(B)

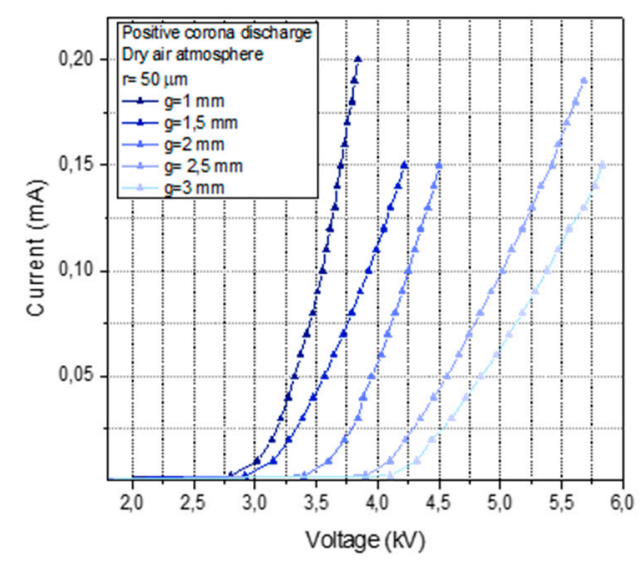

(C)

Figure 9. Representation of leakage $\mathrm{C}-\mathrm{V}$ curve for different electrode separation with radius of (A) $12.5 \mu \mathrm{m}$, (B) $25 \mu \mathrm{m}$ and (C) $50 \mu \mathrm{m}$. 
A)

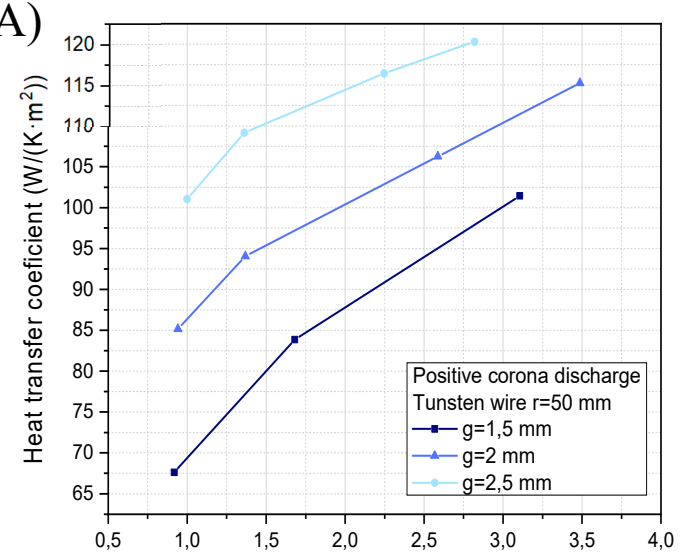

C)

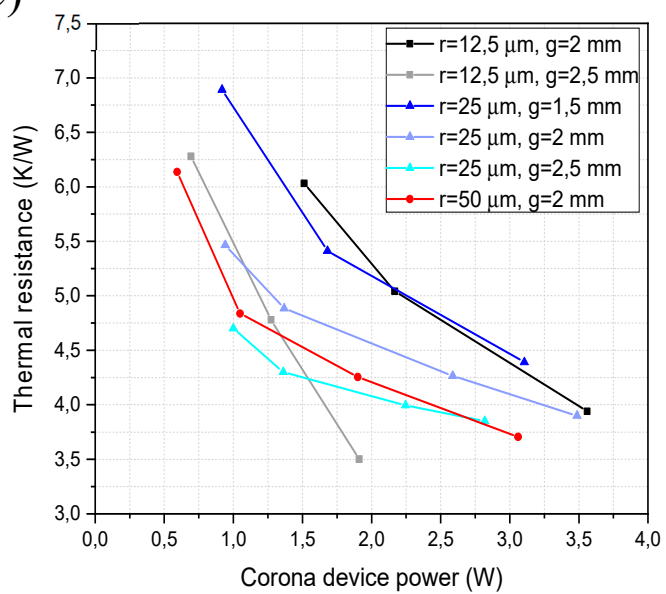

B)

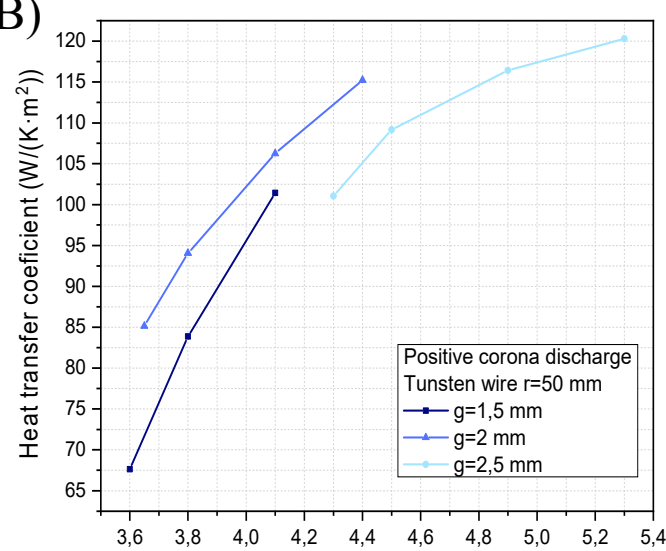

D)

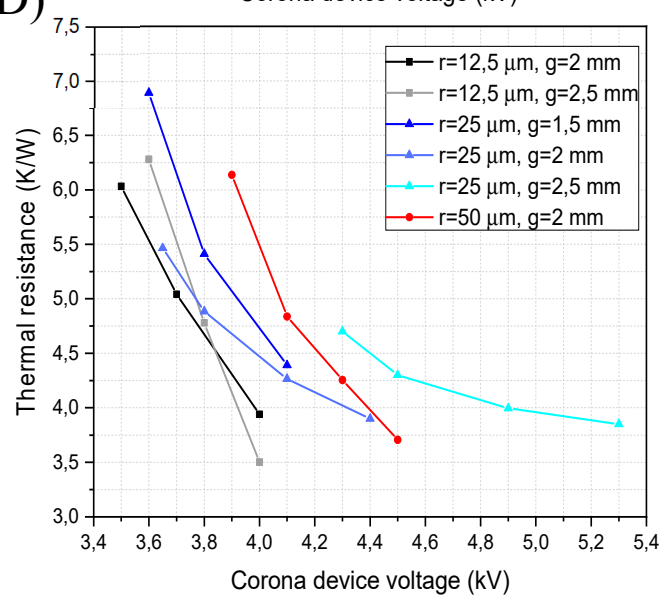

Figure 10. (A) Heat-transfer coefficient for different gaps as a function of device power and (B) operating voltage with electrode diameter of $50 \mu \mathrm{m}$; thermal resistance for different gaps and electrode diameters as a function of device power, (C) and operating voltage (D) shows.

Considering the electrostatic behavior of the results described above, the coefficient of convention is analyzed for these small separations between electrodes. A longer gap seems to be more efficient in power consumption, but it requires higher voltages (Figure 10A,B). This behavior can be explained by the fact that a longer gap will increase ion wind volume, so acceleration of particles will be stronger. This increasement in air speed is traduced in an enhanced heat transfer. In conclusion, a bigger gap seems to be more efficient in power consumption, but operating voltage is a critical parameter design in order to achieve reliability, and a more stable discharge.

\subsection{Global Results and Refrigeration Devices' Comparison}

The high efficiency of TRAID devices per unit of volume and mass is remarkable. A comparison between TRAID, conventional heat sink, and heat sink with a fan is shown in Table 3. Even though power consumption in a corona refrigeration device is around twice as high in the studied sizes, savings in mass and volume are a key parameter in many applications such as aeronautics, where the powers of those devices are negligible: lifting up a heavy fan is more expensive and inefficient than a corona device, and similar performances are possible to obtain. 
Table 3. Thermal performance comparison between different devices.

\begin{tabular}{cccccc}
\hline & Volume $\left(\mathrm{cm}^{3}\right)$ & Mass $(\mathbf{g})$ & $\begin{array}{c}\text { Thermal } \\
\text { Resistance } \\
\mathbf{( K / W )}\end{array}$ & $\begin{array}{c}\text { Heat Transfer per } \\
\text { Unit of Volume } \\
\mathbf{( W / L \cdot K )}\end{array}$ & $\begin{array}{c}\text { Heat Transfer per } \\
\text { Unit of Mass } \\
\mathbf{( W / K g} \cdot \mathbf{K})\end{array}$ \\
\hline Heat Sink 1 & $5 \times 5 \times 2.5=62.5$ & 47 & 10 & 1.6 & 2.13 \\
Heat Sink 2 & $5 \times 3 \times 1.5=22.5$ & 20 & 14 & 3.17 & 3.57 \\
Heat Sink + Fan & $5 \times 5 \times 5=125$ & 88 & 1.2 & 6.67 & 9.47 \\
TRAID & $5 \times 3 \times 1=15$ & 17 & 3.5 & 19.05 & 16.8 \\
\hline
\end{tabular}

\section{Conclusions and Future Directions}

In this study, we have presented a promising design and development based on the configuration of the wire-to-plane fins (electrohydrodynamic heatsink patent) with applications in the microelectronic industry. This specific geometry is the object of study because it is a design capable of being integrated into any electronic system, being light, without moving parts and silent. Different important parameters were studied in the corona phenomenon that directly influence the electrostatic and thermal behavior: corona electrode radii, the electrode separation, and the influence of dielectric barriers to conduct the incoming air and outgoing ionic wind. This means a very precise method is required for manufacturing. The main advantage of this configuration is that, from the point of view of electrical safety, the electric arcs that can be generated during the discharge will remain inside the corona device since the dielectric barriers and the TRAID configuration act as an electrostatic and structural enclosure that prevents the sparks from deviating and affecting the on-board electronics. However, EHD cooling devices have several problems when it comes to their implementation in the industry such as the lack of characterization of the electrode configuration, related to the degradation produced by the electric discharge which is an aggressive environment that leads to the generation of oxides [39,40], and breakage of micrometric wire over time by corrosion. The mechanical characterization (vibrations and thermal fatigue) is a point to study for industrial use since it directly influences the continuity of the corona discharge and consequently the cooling generated by the EHD system.

Author Contributions: M.C., P.M.B. and A.D.L. considered, designed and manufacturing the prototypes for the investigation, analyzed the results obtained and wrote the paper. H.P. supported with modifications in the designs and the interpretation of data obtained. All authors have read and agreed to the published version of the manuscript.

Funding: This work was partially financed by CEDRION C.T.I. S.L and Consejería de Investigación y Educación (Programa de Doctorados Industriales, Comunidad Autónoma de Madrid) through industrial doctoral scholarship IND2017/IND-7799 with Technical University of Madrid.

Acknowledgments: Authors express their gratitude to the Laboratorio de Desarrollo de Productos at the ETSI Industriales of the Universidad Politécnica de Madrid.

Conflicts of Interest: The authors declare no conflict of interest.

\section{References}

1. Johnson, M.J.; Go, D.B. Recent advances in electrohydrodynamic pumps operated by ionic winds: A review. Plasma. Sources Sci. Technol. 2017, 26, 103002. [CrossRef]

2. Zouzou, N.; Dramane, B.; Moreau, E.; Touchard, G. EHD Flow and Collection Efficiency of a DBD ESP in Wire-to-Plane and Plane-to-Plane Configurations. IEEE Trans. Ind. Appl. 2010, 47, 336-343. [CrossRef]

3. Johnson, M.J.; Go, D.B. Piezoelectric transformers for low-voltage generation of gas discharges and ionic winds in atmospheric air. J. Appl. Phys. 2015, 118, 243304. [CrossRef]

4. Ait Said, H.; Nouri, H.; Zebboudj, Y. Analysis of current-voltage characteristics in the wires-to-planes geometry during corona discharge. Eur. Phys. J. Appl. Phys. 2014, 67, 30802. [CrossRef]

5. Conesa, A.J.; Sánchez, M.; León, M.; Cabrera, A. Some geometrical and electrical aspects on the wire-to-cylinder corona discharge. J. Electrost. 2019, 100, 103355. [CrossRef]

6. Zhao, P.; Portugal, S.; Roy, S. Efficient needle plasma actuators for flow control and surface cooling. Appl. Phys. Lett. 2015, 107, 33501. [CrossRef] 
7. Kaci, M.; Said, H.A.; Laifaoui, A.; Aissou, M.; Nouri, H.; Zebboudj, Y. Investigation on the Corona Discharge in Blade-to-Plane Electrode Configuration. Braz. J. Phys. 2015, 45, 643-655. [CrossRef]

8. Drews, A.M.; Cademartiri, L.; Whitesides, G.M.; Bishop, K.J. Electric winds driven by time oscillating corona discharges. J. Appl. Phys. 2013, 114, 143302. [CrossRef]

9. Fylladitakis, E.D.; Moronis, A.X.; Kiousis, K.N. Experimental evaluation of a needle-to-grid EHD pump prototype for semiconductor cooling applications. Int. J. Circuits Syst. Signal Process. 2014, 8, 337-342.

10. Seth, A.; Lee, L. The effect of an electric field in the presence of noncondensable gas on film condensation heat transfer. J. Heat Transf. 1970, 92, 616-620. [CrossRef]

11. Choi, H. Electrohydrodynamic condensation heat transfer. J. Heat Transf. 1968, 90, 257-258. [CrossRef]

12. Chapman, R.; Holmes, E. Condensation of Freon-114 in the presence of a strong nonuniform, alternating electric field. J. Heat Transf. 1970, 92, 616-620.

13. Seyed-Yagoobi, J.; Feng, Y. Mechanism of Annular Two-Phase Flow Heat Transfer Enhancement and Pressure Drop Penalty in the Presence of a Radial Electric Field-Turbulence Analysis. J. Heat Transf. 2003, 125, 478-486.

14. Moss, R.A.; Grey, J. Heat Transfer Augmentation by Steady and Alternating Electric Fields; Stanford University Press: Santa Clara, CA, USA, 1966; pp. 210-255.

15. Bologa, M.K.; Grosu, F.P. The influence of electric fields on heatexchange processes in gases. Appl. Electr. Phenom. 1968, 5, 350-356.

16. Elagin, I.A.; Yakovlev, V.V.; Ashikhmin, I.A.; Stishkov Yu, K. Experimental investigatio of cooling of a plate by ionic wind from a corona-forming wire electrode. Technol. Phys. 2016, 61, 1214-1219. [CrossRef]

17. Wang, H.C.; Jewell-Larsen, N.E.; Mamishev, A.V. Thermal management of microelectronics with electrostatic fluid accelerators. Appl. Therm. Eng. 2013, 51, 190-211. [CrossRef]

18. Go, D.B.; Maturana, R.A.; Fisher, T.S.; Garimella, S.V. Enhancement of External Forced Convection by Ionic Wind. Int. J. Heat Mass Transf. 2008, 51, 6047-6053. [CrossRef]

19. Grimes, R.; Walsh, P.; Walsh, E.; Egan, V. The Effects of Diameter and Rotational Speed on the Aerodynamic Performance of Low-Profile Miniature Radial Flow Fans. In Proceedings of the ASME 2007 5th International Conference on Nanochannels, Microchannels, and Minichannels, Puebla, Mexico, 18-20 June 2007.

20. Rodgers, P.; Eveloy, V.; Pecht, M.G. Limits of air-cooling: Status and challenges. Semiconductor Thermal Measurement and Management Symposium. In Proceedings of the 2005 IEEE Twenty First Annual IEEE, San Jose, CA, USA, 15-17 March 2005.

21. Day, S.W.; Lemire, P.P.; Flack, R.D.; McDaniel, J.C. Effect of Reynolds Number on Performance of a Small Centrifugal Pump. In Proceedings of the ASME/JSME 2003 4th Joint Fluids Summer Engineering Conference, Honolulu, HI, USA, 6 July 2003.

22. Cabeo, N. Philosophia Magnetica; Francesco Suzzi: Ferrara, Italy; Cologne, Germany, 1629.

23. Newton, I. Optics; Printed for Sam, Smith, Benj. Watford; Printers to the Royal Society: London, UK, 1718.

24. Faraday, F. Experimental Researches in Electricity; Faraday: Carlsbad, CA, USA, 1834.

25. Maxwell, J.C. Treatise in Electricity and Magnetism; Oxford University Press: Oxford, UK, 1873.

26. Wilson, B. Treatise on Electricity; C. Corbet: Washington, DC, USA, 1750.

27. Robinson, M. Movement of air in the electric wind of the corona discharge. Am. Inst. Electr. Eng. Part Commun. Electron. 1961, 80, 2. [CrossRef]

28. Kalman, H.; Sher, E. Enhancement of heat transfer by means of a corona wind created by a wire electrode and confined wings assembly. Appl. Therm. Eng. 2001, 21, 265-282. [CrossRef]

29. Rashkovan, A.; Sher, E.; Kalman, H. Experimental optimization of an electric blower by corona wind. Appl. Therm. Eng. 2002, 22, 1587-1599. [CrossRef]

30. Ramadhan, A.A.; Kapur, N.; Summers, J.L.; Thompson, H.M. Numerical analysis and optimization of miniature electrohydrodynamic air blowers. IEEE Trans. Plasma Sci. 2017, 45, 3007. [CrossRef]

31. Ramadhan, A.A.; Kapur, N.; Summers, J.L.; Thompson, H.M. Performance and flow characteristics of miniature EHD air blowers for thermal management applications. J. Electroestatic 2018, 93, 31-42. [CrossRef]

32. Jewell-Larsen, N.E.; Ran, H.; Zhang, Y.; Schwiebert, M.; Tessera, K.H.; Mamishev, A. Electrohydrodynamic (EHD) cooled laptop. Semiconductor Thermal Measurement and Management Symposium. SEMI-THERM 2009. In Proceedings of the 25th Annual IEEE, San Jose, CA, USA, 15-19 March 2009.

33. Jewell-Larsen, N.E.; Joseph, G.G.; Honer, K.A. Scaling Laws for Electrohydrodynamic Air Movers. In Proceedings of theASME/JSME 2011 8th Thermal Engineering Joint Conference, American Society of Mechanical Engineers, Honolulu, HI, USA, 13-17 March 2011. 
34. Puago, H. Disipador de Calor Electro-Hidro-Dinámico. Spanish Patent No. P20183032, 10 March 2018.

35. Belarbi, A.A.; Beriache, M.; Bettahar, A. Experimental study of aero-thermal heat sink performances subjected to impinging air flow. Int. J. Heat Technol. 2018, 36, 4. [CrossRef]

36. Ford, S.; Despeisse, M. Additive manufacturing and sustainability: An exploratory study of the advantages and challenges. J. Clean. Prod. 2016, 137, 1573-1587. [CrossRef]

37. Peek, F.W. Dielectric Phenomena in High Voltage Engineering; McGraw-Hill: New York, NY, USA, 1929.

38. Tirumala, R.; Li, Y.; Pohlman, D.A.; Go, D.B. Corona discharges in sub-millimeter electrode gaps. J. Electrost. 2011, 69, 36-42. [CrossRef]

39. Goldman, A.; Sigmond, R.S. Corona Corrosion of Aluminum in Air. J. Electrochem. Soc. 1985, 132, 12. [CrossRef]

40. Le Ny, R. Evolution des Electrodes sous L' Effect de la Dêcharge Couronne. Ph.D. Thesis, Université de Nantes, Nantes, France, 1981.

(C) 2020 by the authors. Licensee MDPI, Basel, Switzerland. This article is an open access article distributed under the terms and conditions of the Creative Commons Attribution (CC BY) license (http://creativecommons.org/licenses/by/4.0/). 